\title{
True MEN1 or phenocopy? Evidence for geno-phenotypic correlations in MEN1 syndrome
}

\author{
Annamária Kövesdi ${ }^{1,2} \cdot$ Miklós Tóth $^{1} \cdot$ Henriett Butz ${ }^{2,3} \cdot$ Nikolette Szücs $^{1} \cdot$ Beatrix Sármán $^{1} \cdot$ Péter Pusztai $^{1}$. \\ Judit Tőke ${ }^{1}$ - Péter Reismann ${ }^{1}$ - Mónika Fáklya ${ }^{4} \cdot$ Géza Tóth $^{5}$ - Anikó Somogyi ${ }^{1} \cdot$ Katalin Borka $^{6}$ - Annamária Erdei ${ }^{7}$. \\ Endre V. Nagy ${ }^{7}$. Veronika Deák ${ }^{8} \cdot$ Zsuzsanna Valkusz $^{9} \cdot$ Péter Igaz $^{1,10} \cdot$ Attila Patócs $^{2,3} \cdot$ Vince Kornél Grolmusz $^{1,2}$
}

Received: 21 January 2019 / Accepted: 9 April 2019 / Published online: 1 May 2019

(c) The Author(s) 2019

\begin{abstract}
Purpose Multiple endocrine neoplasia type 1 is a rare tumor syndrome caused by germline mutations of MEN1 gene. Phenotype varies widely, and no definitive correlation with the genotype has been observed. Mutation-negative patients with MEN1associated tumors represent phenocopies. By comparing mutation-positive and mutation-negative patients, we aimed to identify phenotype features predictive for a positive genetic test and to evaluate the role of MEN1 mutations in phenotype modulation. Methods Mutation screeening of MEN1 gene by Sanger sequencing and assessment of clinical data of 189 consecutively enrolled probands and relatives were performed at our national and European Reference Center. Multiple ligation probe amplification analysis of MEN1 gene and Sanger sequencing of CDKN1B were carried out in clinically suspicious but MEN1-negative cases.

Results Twenty-seven probands and twenty family members carried MEN1 mutations. Five mutations have not been described earlier. Pronouncedly high number of phenocopies ( $>70 \%)$ was observed. Clinical suspicion of MEN1 syndrome emerged at significantly earlier age in MENI-positive compared to MENI-negative probands. Gastroenteropancreatic neuroendocrine tumors developed significantly earlier and more frequently in carriers compared to non-carriers. Probands with high-impact (frameshift, nonsense, large deletions) mutations, predicted to affect menin function significantly, developed GEP-NETs more frequently compared to low-impact (inframe and missense) mutation carriers.

Conclusions MEN1 phenocopy is common and represents a significant confounder for the genetic testing. GEP-NET under 30 years best predicted a MEN1 mutation. The present study thus confirmed a previous proposal and suggested that GEPNET under 30 years should be considered as a part of the indication criteria for MEN1 mutational analysis.
\end{abstract}

Keywords Multiple endocrine neoplasia type $1 \cdot$ Neuroendocrine tumors $\cdot$ Gastroenteropancreatic neuroendocrine tumor • Phenocopy $\cdot$ Genotype-phenotype associations

Supplementary information The online version of this article (https:// doi.org/10.1007/s12020-019-01932-x) contains supplementary material, which is available to authorized users.

Attila Patócs

patocs.attila@med.semmelweis-univ.hu

1 2nd Department of Medicine, Semmelweis University, Budapest, Hungary

2 "Lendület" Hereditary Endocrine Tumors Research Group, Hungarian Academy of Sciences - Semmelweis University, Budapest, Hungary

3 Department of Laboratory Medicine, Semmelweis University, Budapest, Hungary

4 Kenézy Gyula Hospital, Debrecen, Hungary

5 Markhot Ferenc Hospital, Eger, Hungary
6 2nd Department of Pathology, Semmelweis University, Budapest, Hungary

7 Division of Endocrinology, Department of Medicine, Faculty of Medicine, University of Debrecen, Debrecen, Hungary

8 Kaposi Mór County Hospital, Kaposvár, Hungary

9 1st Department of Medicine, University of Szeged, Szeged, Hungary

10 MTA-SE Molecular Medicine Research Group, Hungarian Academy of Sciences - Semmelweis University, Budapest, Hungary 


\section{Introduction}

Multiple endocrine neoplasia type 1 (MEN1) is a rare, autosomal dominantly inherited tumor syndrome caused by germline mutations of the tumor suppressor MEN1 gene, with an estimated prevalence of 1-10/100,000 individuals $[1,2]$. Most common manifestations include primary hyperparathyroidism (PHPT), pituitary adenomas (PA), and gastroenteropancreatic neuroendocrine tumors (GEP-NET). The tumors of the affected endocrine organs in MEN1 syndrome appear earlier than the sporadic ones. Their penetrance increases with age, although considerable phenotypic variability has been reported $[3,4]$.

Of the three major manifestations, PHPT has the highest penetrance and is considered to appear first in MEN1, although it often remains unrecognised [5]. Recent publications show, that functionally active GEP-NETs, initially frequently diagnosed as sporadic ones, lead to diagnosis of MEN1 in a remarkable proportion of patients [6]. Compared to sporadic tumors, MEN1-associated GEP-NETs are diagnosed 10 years earlier and often in a multiple form $[5,7]$, and their penetrance is as high as $80-90 \%$, reaching nearly that of the parathyroid adenomas [6]. Nonfunctioning GEP-NETs are increasingly recognised due to advanced imaging modalities such as endoscopic ultrasound and thus became the most common type in MEN1 patients [8]. Although MEN1-associated GEP-NETs seem to have a low proliferation rate and long survival has been reported, they should be of particular attention, since they are still the principal cause of death in MEN1 patients [9, 10]. There are only a few studies comparing MEN1-associated versus sporadic GEP-NETs, and there are no unequivocal pieces of information about the possible differences regarding their prognosis [7, 9].

The criteria of diagnosis and the indication for MENI mutation analysis have been described in the Endocrine Society guideline published in 2012 [8]. In $5-10 \%$ of MEN1 patients no mutation of the MENI gene can be found. In these cases simultaneous development of endocrine tumors usually associated with MENI mutations results in phenocopy [8]. Mutations of other genes might be responsible for a MEN1-like phenotype. Rare mutations of the $C D K N 1 B$ gene encoding the cyclin dependent kinase inhibitor p27 causes the MEN1-like MEN4 syndrome [11]. Involvement of the $C a S R, A I P$, and $C D C 73$ genes was also demonstrated as a cause of MEN1-like syndromes [12].

Here, we present our experience with genetic diagnosis of MEN1 syndrome as a Hungarian national reference center from the last 17 years. MEN1 mutation analysis was performed in all patients with clinical suspicion of MEN1 syndrome. MEN1 mutation-positive and mutationnegative subjects were compared in order to identify predictive factors for true MEN1 cases.

\section{Subjects and methods}

\section{Subjects}

MEN1 genetic test is available at our national referral center since 2001. A total of 189 patients, 134 unrelated probands and 55 family members of the mutation-positive pedigrees were examined for germline mutations. Between January 2001 and December 2017, patients were consecutively enrolled from all over Hungary and all data available were collected retrospectively. Of the 134 probands, 104 cases fulfilled the criteria of MEN1 mutational analysis of the Endocrine Society published in 2012 [8]. All available firstdegree relatives of the index cases genetically diagnosed with MEN1 were enrolled. Because of the limited availability of data regarding family history, the familial or sporadic origin of the disease could not be reliably determined in all cases. Clinical information was obtained from the responsible endocrinologists. Diagnosis of the manifestations was established according to the corresponding guidelines [8]. Further regular screening for tumors of the affected organs was performed in mutation-positive cases and in mutation-negative patients presenting with clinical MEN1 syndrome, in line with the widely accepted recommendations [3, 8]. Clinical data were studied together with laboratory, imaging, and histological results.

\section{Genetic analysis}

Detection of disease-causing germline mutations of the MEN1 gene was carried out using genomic DNA isolated from peripheral blood samples in all patients. The coding regions of the MEN1 gene were PCR-amplified and were subjected to Sanger sequencing as described earlier [13, 14]. The new mutations found in MENI gene were considered pathogenic based on their association with clinical MEN1 syndrome. Patients carrying a frameshift, nonsense, splice site mutation or large deletion were considered having a high-impact mutation. Those with a missense or inframe mutations were grouped as low-impact mutation carriers.

Due to the infrequent occurence of both large deletions in the $M E N 1$ gene and mutations of the CDKN1B gene, further genetic analysis was performed in those 15 suspicious, MEN1 mutation-negative cases, who either developed all the three major manifestations, or presented two major manifestations before the age of 40 years. In these probands, MLPA analysis was performed to detect large deletions of the MEN1 gene, using SALSA MLPA probemix kit P017-D1 according to the manufacturer's instructions (MRC-Holland, Amsterdam, The Netherlands). For $C D K N 1 B$ mutation analysis, the two coding exons of $C D K N 1 B$ were PCR-amplified and directly Sanger 
sequenced using predesigned primer pairs (exon 1 forward primer (E1F): 5' CGC TTT GTT TTG TTC GGT TT 3'; exon 1 reverse primer (E1R): 5' ATA CGC CGA AAA GCA AGC TA 3'; exon 2 forward primer (E2F): 5' TAA AAG CCA CTG GGG ATG AC 3'; exon 2 reverse primer (E2R): 5' CAG TGC GTG CTC CTT TAG TG 3'). The $\mathrm{PCR}$ and sequecing protocols were described earlier [13$15]$.

\section{Statistical analysis}

Dell Statistica (data analysis software system), version 13. (Dell Inc. (2016), software.dell.com.) was used for statistical analysis. Correlations between mutational status and clinical manifestations were calculated with $\chi^{2}$ and Fisher's exact test. For examining the differences in age, Student's independent samples' $T$-test was used. For the examination of difference between age-related penetrances Kaplan-Meier curves were plotted and analyzed using log-rank (MantelCox) test. In all comparisons, $p$-value $<0.05$ was considered statistically significant.

\section{Results}

\section{Results of genetic testing}

A total of 189 patients, including 134 unrelated probands and 55 family members were enrolled in this study. MEN1 mutation was identified in 47 cases: 27 probands and 20 family members. All of the 20 family members shared the same mutations as their index relatives. Of the 134 probands, the criteria for MEN1 genetic testing were fulfilled in 104 cases (78 women and 26 men). No mutation was found in those patients who did not fit in the criteria of mutational analysis. Supplementary Table 1 contains detailed clinical and genetic data.

The 104 proband cases with clinical suspicion of MEN1 included 27 (26\%) mutation-positive and 77 (74\%) mutation-negative patients. We found 24 different MEN1 gene mutations among these patients. Three patients carried c.1546_1547insC frameshift mutation in exon 10, two of them developed pancreatic NET under 30 years of age, the third patient had both metastatic pancreatic and bronchial NET. The c.202_206dupGCCCC mutation in exon 2 was identified in two probands. Ten mutations were described in our previous studies [13, 16], and further eight mutations have been reported formerly in the literature. To the best of our knowledge, of the 24 MEN1 gene mutations, five (c.19 C>T, p.Gln7STOP in exon 2; c.1160delA in exon 8; c.1399delG in exon 10; c.166_167insA in exon 2 and c.168delC in exon 2) have not yet been published, thus these were regarded as novel mutations (chromatograms of the mutated sequences can be found in Supplementary Fig. 1). We found 15 mutation-negative cases (19.2\%) that either presented all the three major tumors, or developed two major manifestations before 40 years of age. $C D K N 1 B$ gene sequencing and MLPA analysis of the MEN1 gene were carried out on these samples and in one case the deletion of exon 6 of MEN1 was detected by MLPA.

Twelve mutation-positive index cases had familial MEN1 syndrome, while 11 had sporadic disease. In four cases, the familial or sporadic origin could not be determined. The family history in all MEN1-negative cases was negative, thus they are considered clinically sporadic. Thirty seven of the 77 mutation-negative probands (48.1\%) fulfilled the criteria of clinical MEN1 syndrome, moreover, three of them developed all the three main manifestations of the syndrome (their age at the onset of PHPT was 48, 50 and 53 years; of PA 49, 50 and 53 years; of GEP-NET 46, 47 and 53 years, respectively). In accordance, the proportion of phenocopy within the sporadic patients fulfilling the criteria for clinical MEN1 syndrome (11 MEN1-positive sporadic patients and $37 \mathrm{MEN1}$-negative sporadic patients) was $77.1 \%(37 / 48)$.

\section{Indications of MEN1 mutation analysis}

The first clinical manifestation of the mutation-positive probands was PHPT and GEP-NET, both in $33.3 \%$ of patients, while PA presented in $26.0 \%$ as the first tumor. In one patient, bronchial NET appeared first. In MEN1-negative patients, PHPT, PA, and GEP-NET was the earliest tumor in 49.4, 27.3 and $13.0 \%$ of cases, respectively. Two mutation-negative patients developed adrenal adenomas before the appearance of PHPT, and in $7.8 \%$ information about the first tumor lacked. Figure 1 shows the indications for MEN1 genetic testing. The most common indications were PHPT together with PA and PHPT under 30 years similarly in both MEN1 mutation carriers and non-carriers. It is remarkable that multiple GEP-NETs presented quite often at the beginning of the clinical course of the disease, being a common indication for genetic testing in mutation carriers.

Of the 55 first-degree relatives, 20 carried MEN1 mutations, and six of them did not have any signs or symptoms of MEN1. The youngest patient that underwent MEN1 genetic testing was 6 years old, nonetheless, this patient inherited the mutation.

\section{Incidence and age-related penetrance of MEN1- associated tumors}

The mean follow-up period lasted for 8.5 years. The mortality rate in $M E N 1$ mutation carriers and non-carriers was $14.8(4 / 27)$ and $6.5 \%$ (5/77), respectively, which was not 


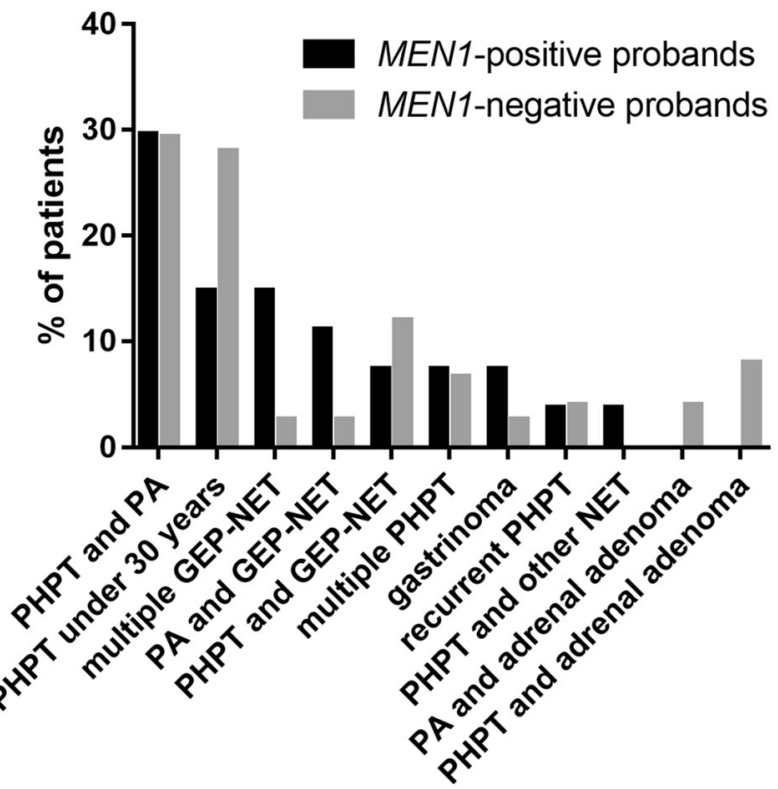

Fig. 1 Indications for MEN1 mutational analysis. The diagram shows manifestations that led to mutational analysis in mutation-positive ( $n=27$, marked with black) and mutation-negative $(n=77$, marked with gray) probands. The criteria for analysis were defined according to the Endocrine Society guideline published in 2012 [8]. The group "multiple GEP-NET" includes both patients with multiple GEP-NETs of the same histological type and patients with multiple GEP-NETs of different subtypes. MEN1 multiple endocrine neoplasia type 1, PHPT primary hyperparathyroidism, PA pituitary adenoma, GEP-NET gastroenteropancreatic neuroendocrine tumor

statistically significant $(p=0.186)$. However, three of the four MEN1 patients died because of GEP-NET (at the age of 35, 44 and 67 years; 10, 19 and 19 years after diagnosis, respectively), compared to only two of the five MEN1negative probands (at the age of 44 and 56; 3 and 3 years after diagnosis, respectively). The suspicion of MEN1 syndrome emerged at significantly earlier age in MEN1 mutation carriers compared to non-carriers (31.4 \pm 12.6 vs. $40.2 \pm 17.3$ years, $p=0.019$, Table 1$)$. The incidence of GEP-NET was significantly higher already at initial presentation in mutation-positive compared to mutation-negative probands $(44.4 \%$ vs. $20.8 \%, p=0.017$, not shown). Significantly higher prevalence of recurrent PHPT $(55.6 \%$ vs. $9.1 \%, p<0.001)$, PA $(66.7 \%$ vs. $39.0 \%$, $p=0.013)$, GEP-NET $(70.4 \%$ vs. $23.4 \%, p<0.001)$ and multiple GEP-NET $(29.6 \%$ vs. $3.9 \%, p<0.001)$ was observed in mutation-positive compared to mutationnegative cases (Table 1). Not only a significantly higher occurence of GEP-NET was associated with the mutant allele, but these tumors also developed significantly earlier in carriers $(31.0 \pm 12.2$ vs. $45.9 \pm 16.1$ years, $p=0.004)$. More than the half of GEP-NETs in mutation-positive probands evolved under 30 years, compared to only $16.7 \%$ of GEP-NETs in non-mutant cases $(p<0.001)$. The combination of at least two of the three major tumors, as expected, correlated significantly with the carrier state. Any two of the three major tumors developed under 30 years of age represented a high predictive value (positive predictive value; $\mathrm{PPV}=72.2 \%$ ) for $M E N 1$ mutation. Apart from the coexistence of the three main manifestations, GEP-NET under 30 years of age best predicted a positive MEN1 genetic test $(\mathrm{PPV}=78.6 \%)$.

The age-related penetrance of the development of MEN1 syndrome suspicion (according to the aforementioned criteria [8]) was significantly higher in mutationpositive compared to mutation-negative probands (Fig. 2); $50 \%$ penetrance was achieved at the age of 27.7 vs. 41.4 years, respectively. Similarly, significantly higher agerelated penetrance of the development of GEP-NET was observed in mutation-positive patients, with $50 \%$ penetrance at the age of 26.8 compared to 46.2 years in mutation-negative probands.

\section{Histological type of tumors}

The most common histological type of MEN1-associated GEP-NET was insulinoma (47.4\%), followed by nonfunctioning pancreatic adenoma (31.6\%) and gastrinoma $(15.8 \%)$, with an overall penetrance of $33.3 \%, 22.2 \%$ and $11.1 \%$ among MEN1 patients, respectively. One patient developed glucagonoma and one patient was diagnosed with an ACTH-secreting NET. Three mutation-carrier probands had NETs of other origin: two patients had bronchial, and one had thymic NET. In contrast, insulinoma was present in only $22.2 \%$ of mutation-negative probands, while gastrinomas were more frequent $(27.8 \%)$, whereas nonfunctioning tumors $(22.2 \%)$ had similar frequencies. Three mutation-negative patients developed ileal carcinoids (16.7\%), one patient had glucagonoma and one had VIPoma. None of the mutation-negative patients had either thymic or bronchial NET.

The majority of PAs in both mutation-positive and -negative probands was functional. The most common type of PA in MEN1-positive probands was prolactinoma (66.7\%). Growth hormone (GH)-PRL-producing, GHproducing and follicle-stimulating hormone (FSH)luteinizing hormone (LH)-producing adenomas were rare $(11.1 \%, 5.6 \%, 5.6 \%$ of PAs, respectively). $11.1 \%$ of PAs were non-functioning. $33.3 \%$ of PAs of mutation-negative patients were GH-producing adenomas. Prolactinomas and non-functioning PAs were less frequent (both had $16.7 \%$ prevalence) and $6.7 \%$ of PAs produced adrenocotricotropic hormone (ACTH). In $26.7 \%$ of MEN1negative cases, the data about hormonal activity was not available. 
Table 1 Comparison of clinical characteristics of MEN1 mutation-positive and mutationnegative probands

\begin{tabular}{|c|c|c|c|c|}
\hline & $\begin{array}{l}\text { Mutation-positive } \\
\text { probands }(n=27)\end{array}$ & $\begin{array}{l}\text { Mutation-negative } \\
\text { probands }(n=77)\end{array}$ & $p$-value & $\begin{array}{l}\% \text { of mutation- } \\
\text { positive } \\
\text { probands (PPV) }\end{array}$ \\
\hline $\begin{array}{l}\text { Age at MEN1 syndrome } \\
\text { suspicion* (years) }\end{array}$ & $31.4 \pm 12.6$ & $40.2 \pm 17.3$ & 0.019 & NA \\
\hline PHPT & $27(100.0 \%)$ & $69(89.6 \%)$ & 0.082 & $27 / 96(28.1 \%)$ \\
\hline Recurrent PHPT* & $15(55.6 \%)$ & $7(9.1 \%)$ & $<0.001$ & $15 / 22(68.2 \%)$ \\
\hline Age at PHPT (years) & $33.4 \pm 13.7$ & $40.3 \pm 17.9$ & 0.082 & NA \\
\hline PHPT under 30 years & $13(48.2 \%)$ & $26(33.8 \%)$ & 0.184 & $13 / 39(33.3 \%)$ \\
\hline PA* & $18(66.7 \%)$ & $30(39.0 \%)$ & 0.013 & $18 / 48(37.5 \%)$ \\
\hline Age at PA (years) & $29.8 \pm 14.2$ & $39.5 \pm 16.5$ & 0.053 & NA \\
\hline GEP-NET* & $19(70.4 \%)$ & $18(23.4 \%)$ & $<0.001$ & 19/37 (51.4\%) \\
\hline Multiple GEP-NET* & $8(29.6 \%)$ & $3(3.9 \%)$ & $<0.001$ & 8/11 (72.7\%) \\
\hline Age at GEP-NET* & $31.0 \pm 12.2$ & $45.9 \pm 16.1$ & 0.004 & NA \\
\hline $\begin{array}{l}\text { GEP-NET under } 30 \text { years* } \\
\text { (years) }\end{array}$ & $11(40.7 \%)$ & $3(3.9 \%)$ & $<0.001$ & $11 / 14(78.6 \%)$ \\
\hline $\begin{array}{l}2 \text { major manifestations under } \\
30 \text { years* }\end{array}$ & $13(48.1 \%)$ & $5(6.5 \%)$ & $<0.001$ & 13/18 (72.2\%) \\
\hline $\mathbf{P H P T}+\mathbf{P A}^{*}$ & $18(66.7 \%)$ & $26(33.8 \%)$ & 0.003 & $18 / 44(40.9 \%)$ \\
\hline PHPT + GEP-NET* $*$ & $19(70.4 \%)$ & $12(15.6 \%)$ & $<0.001$ & $19 / 31(61.3 \%)$ \\
\hline PA + GEP-NET $*$ & $12(44.4 \%)$ & $5(6.5 \%)$ & $<0.001$ & 12/17 (70.6\%) \\
\hline PHPT + PA + GEP-NET $*$ & $12(44.4 \%)$ & $3(3.9 \%)$ & $<0.001$ & $12 / 15(80.0 \%)$ \\
\hline
\end{tabular}

The table presents the frequency of the manifestations regarding genotype (i.e., mutation-positive or -negative), with the related $p$-values, in those probands who fulfilled the criteria of the mutation analysis $(n=104)$. The last column shows the positive predictive value (PPV) of each manifestation, that is: the proportion of mutation-positive probands among all patients carrying the manifestation. The manifestations signed with * mean significant associations. The group "multiple GEP-NET" includes both patients with multiple GEP-NETs of the same histological type as well as patients with multiple GEP-NETs of different subtypes

The bold values are significant

MEN1 multiple endocrine neoplasia type 1, PHPT primary hyperparathyroidism, $P A$ pituitary adenoma, $G E P-N E T$ gastroenteropancreatic neuroendocrine tumor, $P P V$ positive predictive value, $N A$ not applicable

\section{Genotype-phenotype correlations}

Following the concept of distinction between high- and low-impact mutations described above, we separated the mutation-positive probands into two groups to evaluate the possible influence of the mutation type on clinical outcome (Table 2). High-impact mutations included 12 frameshift mutations (44.4\%, six deletions and six insertions), seven nonsense mutations $(25.9 \%)$, one intronic splice-site mutation, and one large deletion. Low-impact mutations encompassed five missense mutations (18.5\%) and one inframe deletion. GEP-NET had a significantly higher frequency among patients carrying high-impact mutations compared to those with low-impact mutations $(81.0 \%$ vs. $33.3 \%, p=0.044)$.

The most frequent location of mutations in the MEN1 gene was exon 2 (40.7\%), followed by exon 10 (18.5\%). No mutations were detected in exons 5 and 7 . No significant association was found between the affected exons and the clinical features.

\section{Discussion}

Our study aimed to collect and analyze the clinical and genetic data of all Hungarian patients who underwent MEN1 genetic testing at our national referral center. The estimated frequency of germline MEN1 mutations in the Hungarian population according to our present data is $0.48 / 100,000$ individuals, which is somewhat lower than expected [1]. However, compared to the recently published multicenter study of the Italian MEN1 database comprising 410 patients [17], the prevalence of MEN1 mutations and the relative number of affected pedigrees in the whole population are similar to our findings. The mutation detection rate (the percentage of the mutation-positive cases among the index patients) in our study was $26 \%$, similarly to the Swedish MEN1 cohort [18]. Additionally, of the 24 different MENI mutations, five have not been documented yet.

Apart from the 27 genetically confirmed MEN1 index cases, 77 unrelated index patients with signs and symptoms 
Fig. 2 Age-related penetrance of the developement of

MEN1 syndrome presumption

(a) and the major

manifestations: PHPT (b), PA

(c), and GEP-NET (d) in MEN1positive vs. MEN1-negative probands with the same manifestation. $P$-values marked with $*$ mean significant associations. MEN1 multiple endocrine neoplasia type 1 , PHPT primary hyperparathyroidism, PA pituitary adenoma, GEP-NET gastroenteropancreatic neuroendocrine tumor
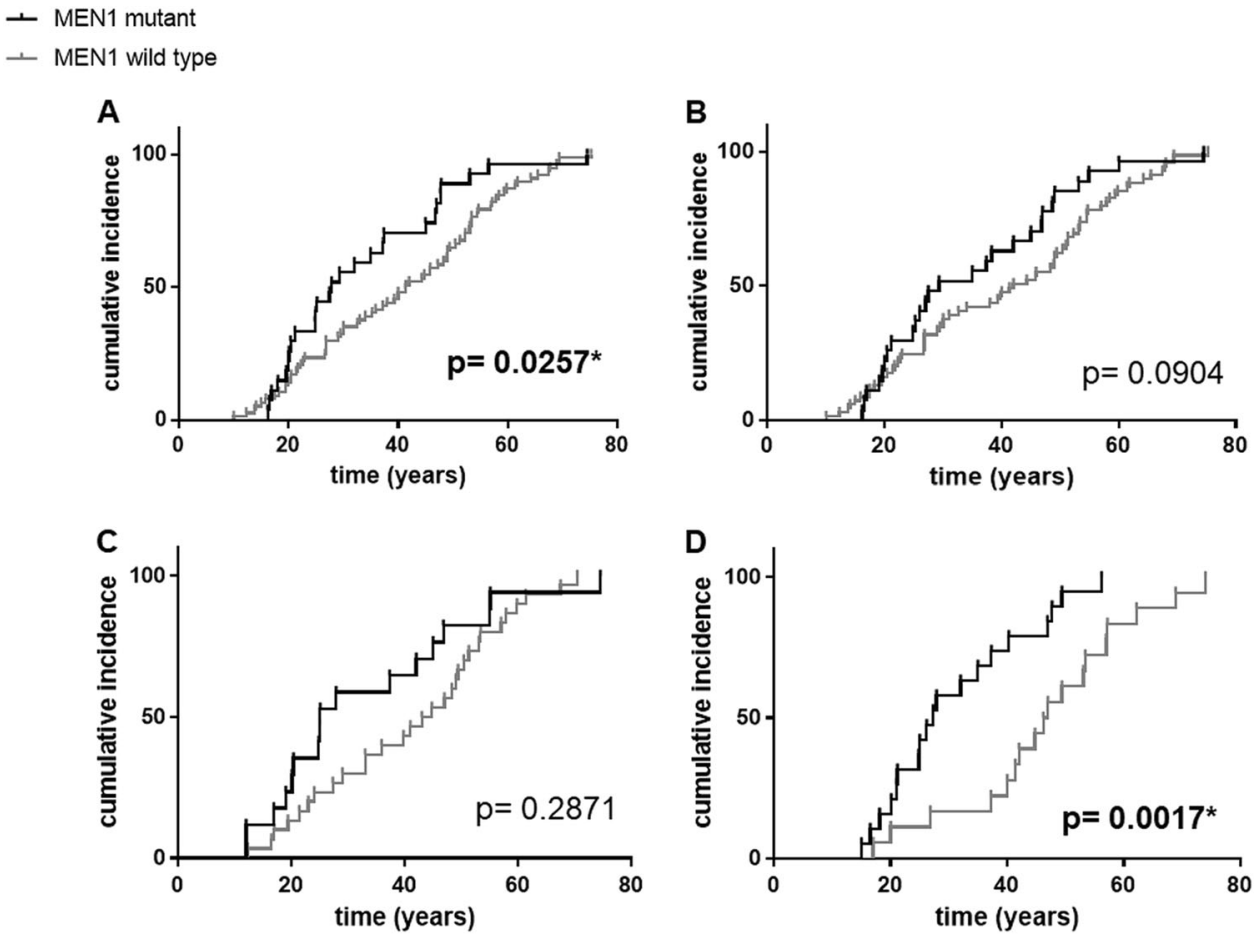

resembling MEN1 syndrome were referred to our laboratory. Neither of these cases had MEN1 mutation. Hence, the percentage of sporadic MEN1 patients with phenocopy was $77.1 \%$ (37/48 cases), higher than previously estimated. Information about the proportion of MEN1 syndrome phenocopy is scarce, especially when distinguishing familial cases from sporadic ones. In these latter cases MEN1 mutations occur far less frequently, in 33-65\% of cases as previously reported [19]. As lately stated, such sporadic co-occurence of the main MEN1-associated endocrine tumors is presumably much more common than thought [20].

The most common indication for MEN1 testing is the combination of PHPT and PA. They also occur frequently in the general population, thus their coexistence cannot be negligible. However, to the best of our knowledge, the exact frequency of the combination of these sporadic tumors is not known. Based on previous studies [20, 21], the cooccurence may be roughly estimated as high as $0.8-5.3 /$ 10,000 individuals, however, still considered a rare disease according to the Orphanet criterion [22].

Considering the low frequency of MEN1 mutations and the high proportion of phenocopy in this population, one specific aim of the present study was to determine key factors which predispose to a positive result of the mutation screening by analyzing the differences between mutationpositive and mutation-negative patients. These findings may be useful for the clinician to identify those patients that most likely carry a MEN1 mutation.
Since mutation-positive probands met the criteria for MEN1 mutation screening at significantly earlier age than mutation-negative probands, we confirmed the previously described findings that younger age is a predisposing factor for a positive result during MEN1 mutation analysis [2]. Moreover, the presence of any two of the three major tumors in patients under 30 years was highly predictive for a MEN1 mutation. A considerable proportion of both $M E N 1$-positive and MEN1-negative patients presented with PHPT either under 30 years or together with PA. This finding reflects the high prevalence and coincidence of these sporadic tumors in the general population, leading to phenocopy [8]; and also raises the issue of whether PHPT under 30 years implies a clear indication for MEN1 mutational analysis.

The presence of GEP-NET implied the strongest predisposing factor regarding MEN1 mutational positivity, already at initial presentation. Moreover, MEN1-associated GEP-NETs developed more than 15 years earlier than sporadic ones. Nonetheless, GEP-NET was the first clinical manifestation in one third of MEN1 probands. Consequently, of all the manifestations, the presence of GEP-NET under 30 years best predicted an underlying germline MEN1 mutation. In accordance, Jensen et al. [23] found that MEN1-associated pancreaticoduodenal endocrine tumors (PDETs) are usually diagnosed one decade earlier than their sporadic counterparts. Furthermore, PDETs have been reported to be frequently the manifestation that leads to MEN1 diagnosis [5]. In line with previous studies, ENETS 
Table 2 Frequency of the manifestations in probands with high- and low-impact mutations, with the related $p$-values

\begin{tabular}{|c|c|c|c|}
\hline & $\begin{array}{l}\text { High-impact } \\
\text { mutation } \\
\text { carriers } \\
(n=21)\end{array}$ & $\begin{array}{l}\text { Low-impact } \\
\text { mutation } \\
\text { carriers }(n=6)\end{array}$ & $p$-value \\
\hline $\begin{array}{l}\text { Age at MEN1 syndrome } \\
\text { suspicion (years) }\end{array}$ & $30.6 \pm 11.6$ & $34.5 \pm 17.6$ & 0.543 \\
\hline PHPT & $21(100.0 \%)$ & $6(100.0 \%)$ & 1.000 \\
\hline Recurrent PHPT & $12(57.1 \%)$ & $3(50.0 \%)$ & 0.557 \\
\hline Age at PHPT (years) & $33.1 \pm 13.3$ & $34.4 \pm 16.9$ & 0.856 \\
\hline PHPT under 30 years & $11(52.4 \%)$ & $2(33.3 \%)$ & 0.362 \\
\hline PA & $14(66.7 \%)$ & $4(66.7 \%)$ & 0.677 \\
\hline Age at PA (years) & $27.9 \pm 14.2$ & $39.0 \pm 12.0$ & 0.230 \\
\hline GEP-NET* & $17(81.0 \%)$ & $2(33.3 \%)$ & 0.044 \\
\hline Multiple GEP-NET & $7(33.3 \%)$ & $1(16.7 \%)$ & 0.430 \\
\hline $\begin{array}{l}\text { Age at GEP-NET } \\
\text { (years) }\end{array}$ & $31.5 \pm 11.9$ & $26.6 \pm 12.5$ & 0.602 \\
\hline $\begin{array}{l}\text { GEP-NET under } \\
30 \text { years }\end{array}$ & $10(47.6 \%)$ & $1(16.7 \%)$ & 0.189 \\
\hline $\begin{array}{l}2 \text { major manifestations } \\
\text { under } 30 \text { years }\end{array}$ & $12(57.1 \%)$ & $1(16.7 \%)$ & 0.080 \\
\hline PHPT + PA & $14(66.7 \%)$ & $4(66.7 \%)$ & 0.677 \\
\hline PHPT + GEP-NET* $*$ & $17(81.0 \%)$ & $2(33.3 \%)$ & 0.044 \\
\hline PA + GEP-NET & $10(47.6 \%)$ & $2(33.3 \%)$ & 0.443 \\
\hline $\begin{array}{l}\text { PHPT + PA + GEP- } \\
\text { NET }\end{array}$ & $10(47.6 \%)$ & $2(33.3 \%)$ & 0.443 \\
\hline
\end{tabular}

The manifestation signed with * mean significant associations. The group "multiple GEP-NET" includes both patients with multiple GEPNETs of the same histological type and patients with multiple GEPNETs of different subtypes

The bold values are significant

MEN1 multiple endocrine neoplasia type 1, PHPT primary hyperparathyroidism, $P A$ pituitary adenoma, GEP-NET gastroenteropancreatic neuroendocrine tumor

consensus guidelines already recommended MEN1 genetic testing in patients with insulinoma before 20 years [24]. De Laat et al. [20] suggested lately, that mutational analysis should be extended to all patients with pancreatic NETs before 20 years of age. The present study, although with a limited number of cases, first evidenced this proposal: GEPNET before 30 years should be especially considered to be included in the criteria of MEN1 mutational analysis. This finding should certainly be confirmed on larger cohorts.

Five hundred and seventy-six different germline mutations of the MEN1 gene were annotated between 1997 and 2015 [25, 26]. Concolino et al. [26] found a portion of $66.5 \%$ of frameshift, nonsense or splice site mutations, while Pardi et al. [27] and Lemos et al. [25] reported almost the same proportion as in our cohort (73\% vs. $74 \%)$. There have been several attempts to find genotype-phenotype correlations regarding MEN1 syndrome. The functional effects of MEN1 mutations have been widely investigated.
One theory states that truncating (frameshift, nonsense) mutations may result in a consequent loss of functional domains, while the non-truncating (missense) forms cause inactivation of functionally critical amino acid residues [25]. Consequently, some studies report about the correlation between frameshift mutations and pancreatic neuroendocrine tumors $[1,28]$. Instead, Machens reported no correlation between the type of mutation and the clinical features [29]. Accordingly with the recommendations of the American College of Medical Genetics and Genomics (ACMG) [30] and upon our results, MEN1 genetic variants might also be categorized as low- and high-impact variants, which confer some limited prognostic differences. In our study, 11 out of 12 MEN1 patients with frameshift mutation had GEP-NET. High-impact MEN1 mutation carriers were more likely to develop GEP-NETs than patients with lowimpact mutations, resulting in a geno-phenotype correlation, which is of importance regarding the genetic counseling and the prognosis of MEN1 syndrome.

Our study presents some limitations, mainly as a consequence of the limited sample size. The clinical information may be incomplete in some cases, and the variable follow-up period did not allow us to draw firm conclusions regarding long-term disease course. The lack of symptoms and the limited availability of sensitive radiological methods presumably contributed to the underestimated proportion of non-functioning GEP-NETs in our cohort. Because of the limited possibility to test patients for large MENI deletions with MLPA and for CDKN1B mutations, some of these mutations could have been missed.

In conclusion, we performed a comprehensive genetic and clinical analysis of the Hungarian MEN1 cohort. As a national and European Reference Center we have built the Hungarian MEN1 database, which may be of great interest in further work coordinated by the European Reference Network on Rare Endocrine Conditions (Endo-ERN, https://endo-ern.eu/). Based on our results a multicentric, international study has been initialised within the EndoERN in order to clarify whether our findings could be confirmed in large cohorts and consequently may lead to the modification of the criteria for MEN1 mutation testing. The beneficial effect of routine screening of presymptomatic individuals has been recently debated [31] and even the timing of genetic testing of presymptomatic indviduals is questioned. The psychological distress and lower healthrelated quality of life in MEN1-positive individuals also indicate that this topic is highly relevant in everyday clinical practice [32]. We revealed a considerable proportion of patients with a high suspicion of MEN1 syndrome but without pathogenic MEN1 mutation, resulting in phenocopy. Thus we aimed to find clinical features that most likely predict an underlying MEN1 mutation by comparing mutation-positive and -negative patients. GEP-NET 
appeared significantly earlier and more frequently in $M E N 1$ positive probands, and its development under 30 years best predicted a positive genetic test. Hereby we confirmed a lately raised suggestion and thus recommend extending the MEN1 mutational analysis to all patients presenting GEPNETs before 30 years. Moreover, MEN1 patients with highimpact MEN1 mutations were more likely to develop GEPNETs revealing an interesting geno-phenotypic association in MEN1 syndrome with potential prognostic consequences regarding genetic counseling. Finally we must add, as it has been previously confirmed many times, that despite the large number of negative results, genetic analysis is inevitable in suspicious cases of the dominantly inherited, highly penetrant MEN1 syndrome [2, 4, 33].

Acknowledgements The authors would like to acknowledge the work of the late Prof. Károly Rácz, founder of the Endocrine Genetics Laboratory of the 2nd Department of Medicine, Semmelweis University, who had a leading role in setting up the nationwide MEN1 genetic testing in Hungary. The authors would like to thank Ms. Mariann Benkő for the excellent technical assistance. Open access funding provided by Semmelweis University (SE).

Funding The study was funded by the Hungarian Academy of Sciences ("Lendulet" grant awarded to Attila Patócs) and of the Hungarian Scientific Research Grant (OTKA, K125231 to Attila Patócs).

\section{Compliance with ethical standards}

Conflict of interest The authors declare that they have no conflict of interest.

Ethical approval The study was conducted in accordance with the Declaration of Helsinki and has been approved by the Scientific and Research Committee of the Medical Research Council of Hungary (ETT-TUKEB 4457/2012/EKU).

Informed consent Written informed consent was acquired from all subjects included in the study.

Publisher's note: Springer Nature remains neutral with regard to jurisdictional claims in published maps and institutional affiliations.

Open Access This article is distributed under the terms of the Creative Commons Attribution 4.0 International License (http://crea tivecommons.org/licenses/by/4.0/), which permits use, duplication, adaptation, distribution, and reproduction in any medium or format, as long as you give appropriate credit to the original author(s) and the source, provide a link to the Creative Commons license, and indicate if changes were made.

\section{References}

1. M.A. Kouvaraki, J.E. Lee, S.E. Shapiro, R.F. Gagel, S.I. Sherman, R.V. Sellin, G.J. Cote, D. Evans, Genotype-phenotype analysis in multiple endocrine neoplasia type 1. Arch. Surg. 137, 641-647 (2002). https://doi.org/10.1001/archsurg.137.6.641

2. J.M. de Laat, R.B. van der Luijt, C.R.C. Pieterman, M.P. Oostveen, A.R. Hermus, O.M. Dekkers, W.W. de Herder, A.N. van der Horst-Schrivers, M.L. Drent, P.H. Bisschop, B. Havekes, M.R. Vriens, G.D. Valk, MEN1 redefined, a clinical comparison of mutation-positive and mutation-negative patients. BMC Med. 14, 1-9 (2016). https://doi.org/10.1186/ s12916-016-0708-1

3. M.L. Brandi, R.F. Gagel, A. Angeli, J.P. Bilezikian, P. BeckPeccoz, C. Bordi, B. Conte-Devolx, A. Falchetti, R.G. Gheri, A. Libroia, C.J.M. Lips, G. Lombardi, M. Mannelli, F. Pacini, B.A.J. Ponder, F. Raue, B. Skogseid, G. Tamburrano, R.V. Thakker, N. W. Thompson, P. Tomassetti, F. Tonelli, J. Wells, S.J. Marx, Consensus: Guidelines for diagnosis and therapy of MEN type 1 and type 2. J. Clin. Endocrinol. Metab. 86, 5658-5671 (2001). https://doi.org/10.1210/jcem.86.12.8070

4. A. Falchetti, Genetics of multiple endocrine neoplasia type 1 syndrome: what's new and what's old. F1000Research 6, 73 (2017). https://doi.org/10.12688/f1000research.7230.1

5. M.V. Davì, L. Boninsegna, L. Dalle Carbonare, M. Toaiari, P. Capelli, A. Scarpa, G. Francia, M. Falconi, Presentation and outcome of pancreaticoduodenal endocrine tumors in multiple endocrine neoplasia type 1 syndrome. Neuroendocrinology 94, 58-65 (2011). https://doi.org/10.1159/000326164

6. F. Giudici, T. Cavalli, F. Giusti, G. Gronchi, G. Batignani, F. Tonelli, M.L. Brandi, Natural history of MEN1 GEP-NET: singlecenter experience after a long follow-up. World J. Surg. 41, 2312-2323 (2017). https://doi.org/10.1007/s00268-017-4019-2

7. F. Tonelli, F. Giudici, G. Fratini, M.L. Brandi, Pancreatic endocrine tumors in multiple endocrine neoplasia type 1 syndrome: review of literature. Endocr. Pract. 17(Suppl 3), 33-40 (2011). https://doi.org/10.4158/EP10376.RA

8. R.V. Thakker, P.J. Newey, G.V. Walls, J. Bilezikian, H. Dralle, P. R. Ebeling, S. Melmed, A. Sakurai, F. Tonelli, M.L. Brandi, Clinical practice guidelines for multiple endocrine neoplasia type 1 (MEN1). J. Clin. Endocrinol. Metab. 97, 2990-3011 (2012). https://doi.org/10.1210/jc.2012-1230

9. S. Chiloiro, F. Lanza, A. Bianchi, G. Schinzari, M.G. Brizi, A. Giampietro, V. Rufini, F. Inzani, A. Giordano, G. Rindi, A. Pontecorvi, L. De Marinis, Pancreatic neuroendocrine tumors in MEN1 disease: a mono-centric longitudinal and prognostic study. Endocrine 60, 362-367 (2018). https://doi.org/10.1007/s12020017-1327-0

10. S.L. D’Souza, B.J. Elmunzer, J.M. Scheiman, Long-term follow-up of asymptomatic pancreatic neuroendocrine tumors in multiple endocrine neoplasia type i syndrome. J. Clin. Gastroenterol. 48, 458-461 (2014). https://doi.org/10.1097/MCG. 0000000000000062

11. R. Alrezk, F. Hannah-Shmouni, C.A.M.E.N.4 Stratakis, and CDKN1B mutations: the latest of the MEN syndromes. Endocr. Relat. Cancer 24, T195-T208 (2017). https://doi.org/10.1530/ ERC-17-0243

12. J.J.O. Turner, P.T. Christie, S.H.S. Pearce, P.D. Turnpenny, R.V. Thakker, Diagnostic challenges due to phenocopies: lessons from Multiple Endocrine Neoplasiatype1 (MEN1). Hum. Mutat. 31, E1089-101 (2010). https://doi.org/10.1002/humu.21170

13. K. Balogh, L. Hunyady, A. Patocs, P. Gergics, Z. Valkusz, M. Toth, K. Racz, MEN1 gene mutations in Hungarian patients with multiple endocrine neoplasia type 1. Clin. Endocrinol. 67, 727-734 (2007). https://doi.org/10.1111/j.1365-2265.2007.02953.x

14. V.K. Grolmusz, K. Borka, A. Kövesdi, K. Németh, K. Balogh, C. Dékány, A. Kiss, A. Szentpéteri, B. Sármán, A. Somogyi, É. Csajbók, Z. Valkusz, M. Tóth, P. Igaz, K. Rácz, A. Patócs, MEN1 mutations and potentially MEN1-targeting miRNAs are responsible for menin deficiency in sporadic and MEN1 syndromeassociated primary hyperparathyroidism. Virchows Arch. 471, 401-411 (2017). https://doi.org/10.1007/s00428-017-2158-3

15. V.K. Grolmusz, B. Stenczer, T. Fekete, G. Szendei, A. Patocs, K. Racz, P. Reismann, Lack of association between C385A 
functional polymorphism of the fatty acid amide hydrolase gene and polycystic ovary syndrome. Exp. Clin. Endocrinol. Diabetes 121, 338-342 (2013). https://doi.org/10.1055/s-0033-1337941

16. K. Balogh, A. Patócs, J. Majnik, F. Varga, G. Illyés, L. Hunyady, K. Racz, Unusual presentation of multiple endocrine neoplasia type 1 in a young woman with a novel mutation of the MEN1 gene. J. Hum. Genet. 49, 380-386 (2004). https://doi.org/10.1007/ s10038-004-0163-2

17. F. Marini, F. Giusti, C. Fossi, F. Cioppi, L. Cianferotti, L. Masi, F. Boaretto, S. Zovato, F. Cetani, A. Colao, M.V. Davì, A. Faggiano, G. Fanciulli, P. Ferolla, D. Ferone, P. Loli, F. Mantero, C. Marcocci, G. Opocher, P. Beck-Peccoz, L. Persani, A. Scillitani, F. Guizzardi, A. Spada, P. Tomassetti, F. Tonelli, M.L. Brandi, Multiple endocrine neoplasia type 1: analysis of germline MEN1 mutations in the Italian multicenter MEN1 patient database. Endocrine 62, 215-233 (2018). https://doi.org/10.1007/s12020-018-1566-8

18. E. Tham, U. Grandell, E. Lindgren, G. Toss, B. Skogseid, M. Nordenskjöld, Clinical testing for mutations in the MEN1 gene in Sweden: a report on 200 unrelated cases. J. Clin. Endocrinol. Metab. 92, 3389-3395 (2007). https://doi.org/10.1210/jc.2007-0476

19. M. Giacché, A. Panarotto, L. Mori, L. Daffini, M.C. Tacchetti, I. Pirola, E. Agabiti Rosei, M. Castellano, A novel menin gene deletional mutation in a little series of Italian patients affected by apparently sporadic multiple endocrine neoplasia type 1 syndrome. J. Endocrinol. Invest. 35, 124-128 (2012). https://doi.org/ 10.1007/BF03345419

20. J.M. de Laat, R.S. van Leeuwaarde, G.D. Valk, The Importance of an Early and Accurate MEN1 Diagnosis. Front. Endocrinol. 9, 533 (2018). https://doi.org/10.3389/fendo.2018.00533

21. M.W. Yeh, P.H.G. Ituarte, H.C. Zhou, S. Nishimoto, I.-L.A. Liu, A. Harari, P.I. Haigh, A.L. Adams, Incidence and prevalence of primary hyperparathyroidism in a racially mixed population. J. Clin. Endocrinol. Metab. 98, 1122-1129 (2013). https://doi.org/ 10.1210/jc.2012-4022

22. Orphanet: an online database of rare diseases and orphan drugs. Copyright, INSERM 1997. http://www.orpha.net. Accessed 30 March 2019

23. R.T. Jensen, M.J. Berna, D.B. Bingham, J.A. Norton, Inherited pancreatic endocrine tumor syndromes: Advances in molecular pathogenesis, diagnosis, management, and controversies. Cancer 113, 1807-1843 (2008). https://doi.org/10.1002/cncr.23648

24. M. Falconi, B. Eriksson, G. Kaltsas, D.K. Bartsch, J. Capdevila, M. Caplin, B. Kos-Kudla, D. Kwekkeboom, G. Rindi, G. Kloppel, N. Reed, R. Kianmanesh, R.T. Jensen, ENETS Consensus Guidelines Update for the Management of Patients with Functional Pancreatic Neuroendocrine Tumors and Non-Functional Pancreatic Neuroendocrine Tumors. Neuroendocrinology 103, 153-171 (2016). https://doi.org/10.1159/000443171

25. M.C. Lemos, R.V. Thakker, Multiple endocrine neoplasia type 1 (MEN1): analysis of 1336 mutations reported in the first decade following identification of the gene. Hum. Mutat. 29, 22-32 (2008). https://doi.org/10.1002/humu.20605

26. P. Concolino, A. Costella, E. Capoluongo, Multiple endocrine neoplasia type 1 (MEN1): An update of 208 new germline variants reported in the last nine years. Cancer Genet. 209, 36-41 (2016). https://doi.org/10.1016/j.cancergen.2015.12.002

27. E. Pardi, S. Borsari, F. Saponaro, F. Bogazzi, C. Urbani, S. Mariotti, F. Pigliaru, C. Satta, F. Pani, G. Materazzi, P. Miccoli, L. Grantaliano, C. Marcocci, F. Cetani, Mutational and large deletion study of genes implicated in hereditary forms of primary hyperparathyroidism and correlation with clinical features. PLoS ONE 12, 1-22 (2017). https://doi.org/10.1371/journal.pone. 0186485

28. I. Christakis, W. Qiu, S.M. Hyde, G.J. Cote, E.G. Grubbs, N.D. Perrier, J.E. Lee, Genotype-phenotype pancreatic neuroendocrine tumor relationship in multiple endocrine neoplasia type 1 patients: A 23-year experience at a single institution. Surgery 163, 212-217 (2018). https://doi.org/10.1016/j.surg.2017.04.044

29. A. Machens, L. Schaaf, W. Karges, K. Frank-Raue, D.K. Bartsch, M. Rothmund, U. Schneyer, P. Goretzki, F. Raue, H. Dralle, Agerelated penetrance of endocrine tumours in multiple endocrine neoplasia type 1 (MEN1): a multicentre study of 258 gene carriers. Clin. Endocrinol. 67, 613-622 (2007). https://doi.org/10. 1111/j.1365-2265.2007.02934.x

30. S. Richards, N. Aziz, S. Bale, D. Bick, S. Das, J. Gastier-Foster, W.W. Grody, M. Hegde, E. Lyon, E. Spector, K. Voelkerding, H. L. Rehm, Standards and guidelines for the interpretation of sequence variants: a joint consensus recommendation of the American College of Medical Genetics and Genomics and the Association for Molecular Pathology. Genet. Med. 17, 405-424 (2015). https://doi.org/10.1038/gim.2015.30

31. J. Manoharan, F. Raue, C.L. Lopez, M.B. Albers, C. Bollmann, V. Fendrich, E.P. Slater, D.K. Bartsch, Is routine screening of young asymptomatic MEN1 patients necessary? World J. Surg. (2017) https://doi.org/10.1007/s00268-017-3992-9

32. R.S. van Leeuwaarde, C.R.C. Pieterman, E.M.A. Bleiker, O.M. Dekkers, A.N. van der Horst-Schrivers, A.R. Hermus, W.W. de Herder, M.L. Drent, P.H. Bisschop, B. Havekes, M.R. Vriens, G. D. Valk, High fear of disease occurrence is associated with low quality of life in patients with multiple endocrine neoplasia type 1: results from the Dutch MEN1 Study Group. J. Clin. Endocrinol. Metab. 103, 2354-2361 (2018). https://doi.org/10.1210/jc.201800259

33. J.R. Burgess, B. Nord, R. David, T.M. Greenaway, V. Parameswaran, C. Larsson, J.J. Shepherd, B.T. Teh, Phenotype and phenocopy: the relationship between genotype and clinical phenotype in a single large family with multiple endocrine neoplasia type 1 (MEN 1). Clin. Endocrinol. 53, 205-211 (2000). https:// doi.org/10.1046/j.1365-2265.2000.01032.x 